\title{
Clinical Manifestation of Patients Who Died Due to COVID-19; A Retrospective Study from Qom-Iran
}

\author{
Ahmad Hormati, MD ${ }^{1,2 *}$; Seyed Yaser Foroghi Ghomi, MD ${ }^{3 \#}$; Masoudreza Sohrabi, MD, PhD²; Saeede Jafari, MSc'; Amir Jabbari, MD ${ }^{4}$; Reza \\ Aminnejad, MD ${ }^{5}$; Mahboubeh Afifian, MSc ${ }^{6}$; Elham RakhshanKhah ${ }^{2}$; Sajjad Ahmadpour, PhD ${ }^{1}$ \begin{abstract}
${ }^{2}$ Gastrointestinal and Liver Diseases Research Center (GILDRC), Iran University of Medical Sciences, Tehran, Iran ${ }^{3}$ Clinical Research Development Center, Qom University of Medical Sciences, Qom, Iran

${ }^{4}$ Department of Internal Medicine, Qom University of Medical Sciences, Qom, Iran

${ }^{5}$ Department of Anesthesiology and clinical care, Qom University of Medical Sciences, Qom, Iran

${ }^{6}$ Health Information and Technology, Tehran University of Medical Sciences, Tehran, Iran
\end{abstract} \\ 'Gastroenterology and Hepatology Diseases Research Center, Qom University of Medical Sciences, Qom, Iran
}

\begin{abstract}
Background: The coronavirus disease 2019 (COVID-19) has become a pandemic health problem worldwide. In this study, we attempted to explain the clinical and laboratories characteristics of non-surviving patients, to identify the probable factors affecting disease progression.

Methods: In a retrospective study, we assessed the data from dead adult patients who were hospitalized and laboratory diagnosed with COVID-19 during March 2020. The data were obtained from electronic medical records. Moreover, a checklist including demographic, clinical, laboratorial, imaging, and treatment data was completed for each one of the patients. In case of lack of information, a member of the research team contacted the first-degree relatives via phone.

Results: Totally, 50 patients were enrolled in this study. The mean age was $68.0 \pm 14.1$ years. Of them, $29(58 \%)$ patients were male. Notably, the median (IQR) hospitalization time was $4.0(2.7-6.2)$ days and the duration between the first symptoms to death was 10.0 (5.0-14.5) days. Also, pre-existing morbidity was reported in 42 (84\%) patients, and hypertension was the most common one with $28(54 \%)$ patients. Interestingly, body temperature more than $37.5^{\circ} \mathrm{C}$ was reported in only $20(40 \%)$ patients. Nevertheless, neutrophilia $\left(\geq 710^{\%} / \mathrm{L}\right)$ and lymphopenia $(<1.0109 / \mathrm{L})$ were observed in $27(54 \%)$ and $29(58 \%)$ patients, respectively. Also, elevated levels of creatinine, lactate dehydrogenase (LDH), erythrocyte sedimentation rate (ESR), and C-reactive protein (CRP) were common, which may be indicators of aggravation of the patients' status.

Conclusion: Besides age and underlying diseases, elevated creatinine level, neutrophil count, and the inflammatory indices along with the reduced lymphocyte count can be considered as indicators of disease progression. Hence, they should be considered for admission and surveillance of patients.

Keywords: Clinical manifestation, COVID-19, Iran, Middle East, Mortality

Cite this article as: Hormati A, Foroghi Ghomi SY, Sohrabi M, Jafari S, Jabbari A, Aminnejad R, et al. Clinical manifestation of patients who died due to COVID-19; a retrospective study from Qom-Iran. Arch Iran Med. 2020;23(12):864-869. doi: 10.34172/ aim.2020.115.
\end{abstract}

Received: April 27, 2020, Accepted: September 8, 2020, ePublished: December 1, 2020

\section{Introduction}

A new RNA virus from the betacoronavirus family named severe acute respiratory syndrome coronavirus 2 (SARS-CoV-2) was first recognized in Wuhan, China, in December 2019. Since then, the virus has contaminated all parts of the world and become an endemic health problem. ${ }^{1}$ In the Middle East, the outbreak of coronavirus disease 2019 (COVID-19) was reported in Qom, Iran, in February 2020, for the first time. The virus was rapidly detected in the mass population in this city as well as other cities. The city of Qom is located in the center of Iran with many industrial and religious centers and many daily visitors, resulting in many travels. The main route of transmission is person-to-person transmission in society and family settings; however, other routes of transmission need to be considered. Despite the fact that the virus mainly affects the respiratory system, other vital organ can also be affected seriously. ${ }^{2-4}$ Therefore, we can assume a wide spectrum of presentations in this situation. In fact, the common clinical presentations of COVID-19 are cough, dyspnea, fatigue, fever, chest pain, and myalgia. Moreover, alteration of complete blood count differential, and abnormal radiographic finding in chest CT scans are also reported. ${ }^{5-8}$ The mortality rate of COVID-19 is reported between $2 \%$ and $16 \%$ based on age. ${ }^{9}$ Furthermore, the rate of mortality may increase $2-10$ folds among patients admitted to the intensive care unit (ICU) with preexisting morbidities such as cardiovascular diseases and diabetes. ${ }^{10}$ In this regard, Chen et al reported that mortality in ICU admitted patients reached $4.3 \%$. Accordingly, the main risk factors of mortality are advanced age, shortness of breath or dyspnea, low hemoglobin level, and having underlying 
comorbidities. ${ }^{11} \mathrm{Li}$ et al reported that the mortality rates for patients with hypertension, cerebrovascular diseases, and diabetes were two-, three-, and two-folds higher, respectively, in patients admitted to the ICU. ${ }^{12}$

The clinical characteristics of expired patients in our region has not been reported. In this study, we summarized the clinical features of expired cases with COVID-19 from Qom. The purpose of this study is to identify critically ill COVID-19 patients of early and to reduce their mortality.

\section{Patients and Methods}

Patients

In this retrospective study, we reviewed medical files of 50 secondary non-surviving patients with COVID-19 who were hospitalized in March 2020. The patients were admitted to Shahid Beheshti general hospital, which is the referral hospital for COVID-19 patients. All of them were laboratory diagnosed with COVID-19 based on the WHO guideline (detection of virus RNA was considered as confirmed positive result). Due to rapidity and the emergency situation, the data for all patients could be not completed; so, we selected the patients who had almost all the related data.

\section{Data Collection}

All data were obtained from the electronic file of each patient. Moreover, a checklist including demographic, clinical presentation, clinical assessment, and laboratories data was completed. In case of any lack of data, a member of the team contacted the first-degree relative of the patient. In the next step, data was entered into the computerized database. Afterward, two experienced clinicians reviewed the data.

\section{Laboratory Data}

All activities, including sample collection and transfer, as well as lab safety issues were performed in compliance with the WHO guidelines for COVID-19 (WHO laboratory testing strategy recommendations for COVID-19: Interim guidance 2020).

Venous blood samples, as the standard method, were then obtained on the first day of admission. Variables including the alanine aminotransferase (ALT), aspartate aminotransferase (AST), alkaline phosphatase (ALP), uric acid (UA), blood urea nitrogen (BUN), creatinine, and C-reactive protein (CRP) were analyzed using the diagnostic kits from Pars Azmoon Company (Pars Azmoon Co., Tehran, Iran) and Auto-Analyzer BS200 (Mindray, Shenzhen, China).

Ethylene diamine tetra acetic acid (EDTA)-containing tubes were used for complete blood count $(\mathrm{CBC})$ and differential blood counts using an automated blood cell counter (Sysmex K1000, Hamburg, Germany). For RNA extraction, a nasopharyngeal swab into viral transport media was used according to the manufacturer's instructions. Subsequently, a one-step real-time polymerase chain reaction (PCR) was performed by an assigned diagnostic laboratory, which was confirmed by the Ministry of Health based on universal protocols. All patients underwent a standard chest CT scan. Afterward, the results of the imaging were acquired via electronic reports for each patient.

\section{Statistical Analysis}

Means (SD) and medians (IQR) were presented for normal and non-normal continuous variables, respectively. Normal distribution was checked using Shapiro-Wilk test and also normal probability plot (Q-Q plot). Categorical variables were expressed as number (\%). All statistical analyses were performed using SPSS, version 20.0.

\section{Results}

In the present study, 50 expired patients with complete medical files were selected. Accordingly, the mean age was $68.0 \pm 14.1$ years. Of them, $29(58 \%)$ subjects were male. The median length of hospitalization was 4 (2.7-6.2) days and the median course of disease was 10 (5-14.5) days. Also, 42 (84\%) of the patients had preexisting comorbidities, the most common of which were cardiovascular disease, hypertension, and diabetes, involving 15 (30\%), $28(56 \%)$, and 14 (28\%) of patients, respectively. Smoking was found in $12(24 \%)$ patients (Table 1). The majority of the patients had fever between 37.5 and $38^{\circ} \mathrm{C}$. Moreover, the most common complaints were shortness of breath in $44(88 \%)$, fatigue/weakness in $32(64 \%)$, and coughing in $32(64 \%)$ patients. Quick SOFA score more than 2 was seen in $11(22 \%)$ patients (Table 2).

Table 1. Characteristics of Studied Patients

\begin{tabular}{lc}
\hline Variables & Total $(\mathbf{n}=\mathbf{5 0})$ \\
$\mathbf{N o .}(\mathbf{\%})$
\end{tabular}


Table 2. Clinical Symptoms Among Studied Patients

\begin{tabular}{|c|c|}
\hline Variables & $\begin{array}{c}\text { Total }(\mathbf{n}=50) \\
\text { No. }(\%)\end{array}$ \\
\hline \multicolumn{2}{|l|}{ Body temperature } \\
\hline$<37.5$ & $30(60)$ \\
\hline $37.5-38$ & $19(38)$ \\
\hline$>38.1$ & $1(2)$ \\
\hline Sore throat & $22(44)$ \\
\hline Headache & $7(14)$ \\
\hline Chest pain & $21(42)$ \\
\hline Coughing & $32(64)$ \\
\hline Sputum production & $3(6)$ \\
\hline Fatigue & $32(64)$ \\
\hline Myalgia/arthralgia & $8(16)$ \\
\hline Chills & $15(30)$ \\
\hline Sweating & $1(2)$ \\
\hline Shortness of breath & $44(88)$ \\
\hline Dizziness & $11(22)$ \\
\hline Nausea and vomiting & $14(28)$ \\
\hline Abdominal pain & $11(22)$ \\
\hline Diarrhea & $12(24)$ \\
\hline Respiratory rate $(\geq 24)$ & $8(16)$ \\
\hline Pulse rate $(\geq 120)$ & $7(14)$ \\
\hline Quick SOFA ( $\geq 2$ ) & $11(22)$ \\
\hline
\end{tabular}

Table 3 illustrates the laboratory results on admission. White blood cell (WBC) count more than $10 \times 10^{9}$ was seen in 17 (34\%) patients. Moreover, lymphopenia and neutrophilia were observed in 29 (58\%) and 27 (54\%) patients, respectively. An interesting finding was the hemoglobin $(\mathrm{Hb})$ concentration which was $>10 \mathrm{~g} / \mathrm{dL}$ in the majority of the patients. The level of CRP $\geq 25 \mathrm{mg} / \mathrm{L}$ was also seen in $47(98 \%)$ patients. In addition, lactate dehydrogenase $(\mathrm{LDH})>500 \mathrm{U} / \mathrm{L}$ was reported in 34 (87\%) patients. Elevated erythrocyte sedimentation rate (ESR) $\geq 20$ in $31(82 \%), \mathrm{SpO}_{2}<90 \mathrm{~mm} \mathrm{Hg}$ in $37(74 \%)$, and international normalized ratio (INR) $\geq 1.3$ in 21 (44\%) patients were seen. Furthermore, elevated BUN $\geq 20$ in 37 (74\%) patients and creatinine $\geq 1.3$ in $35(70 \%)$ patients were observed. Also, AST $\geq 40$ and ALT $\geq 40$ were reported in $33(73 \%)$ and $15(33 \%)$ patients, respectively. CT scan finding illustrated that all the patients had lung injuries. Moreover, all the patients had ground glass feature, in which consolidation was reported in 23 (46\%) patients (Table 3).

Moreover, the most common complication was respiratory failure in $50(100 \%)$ followed by acute respiratory distress syndrome (ARDS) in 49 (98\%), acute kidney injury in 31 (62\%), and acidosis in 24 (48\%) patients (Table 4).

\section{Discussion}

This study presents one of the preliminary results regarding COVID-19 mortality in the city of Qom. This
Table 3. Laboratories Results Among Studied Patients

\begin{tabular}{|c|c|}
\hline Variables (Normal Range) & $\begin{array}{c}\text { Total }(n=50) \\
\text { No. }(\%)\end{array}$ \\
\hline \multicolumn{2}{|l|}{ WBC $\left(4-9.5 \times 10^{9} / \mathrm{L}\right)$} \\
\hline Median (IQR) & $8.7(6.5-12.1)$ \\
\hline$<4.0$ & $3(6)$ \\
\hline $4-10$ & $30(60)$ \\
\hline$>10.0$ & $17(34)$ \\
\hline \multicolumn{2}{|l|}{ Neutrophil (1.8-7.4 ×10\%/L) } \\
\hline Median (IQR) & $7(5.8-10.3)$ \\
\hline$<7.0$ & $23(46)$ \\
\hline$\geq 7.0$ & $27(54)$ \\
\hline \multicolumn{2}{|l|}{ Lymphocyte (1.0-4.4 ×10\%/L) } \\
\hline Median (IQR) & $0.8(0.5-1.2)$ \\
\hline$<1.0$ & $29(58)$ \\
\hline$\geq 1.0$ & $21(42)$ \\
\hline \multicolumn{2}{|l|}{ Platelets $\left(150-400 \times 10^{9} / \mathrm{L}\right)$} \\
\hline Mean \pm SD & $181.5 \pm 65.0$ \\
\hline$>150000$ & $36(72)$ \\
\hline $100000-150000$ & $10(20)$ \\
\hline$<100000$ & $4(8)$ \\
\hline \multicolumn{2}{|l|}{ Hemoglobin (12-16 g/dL) } \\
\hline Mean \pm SD & $12.5 \pm 2.3$ \\
\hline$<10$ & $8(16)$ \\
\hline$\geq 10$ & $42(84)$ \\
\hline \multicolumn{2}{|l|}{ Sodium (135-148 mmol/L) } \\
\hline Median (IQR) & $136.0(133.0-141.0)$ \\
\hline$<135$ & $20(40)$ \\
\hline$\geq 135$ & $30(60)$ \\
\hline \multicolumn{2}{|l|}{ Potassium (3.5-5.3 mmol/L) } \\
\hline Median (IQR) & $4.3(3.8-4.8)$ \\
\hline$<4$ & $18(36)$ \\
\hline$\geq 4$ & $32(64)$ \\
\hline \multicolumn{2}{|l|}{ BUN (7-20 mg/dL) } \\
\hline Median (IQR) & $30.0(18.7-47.0)$ \\
\hline$<20$ & $13(26)$ \\
\hline$\geq 20$ & $37(74)$ \\
\hline \multicolumn{2}{|l|}{ Creatinine $(0.6-1.4 \mathrm{mg} / \mathrm{dL})$} \\
\hline Median (IQR) & $1.4(1.1-2.3)$ \\
\hline$<1.3$ & $15(30)$ \\
\hline$\geq 1.3$ & $35(70)$ \\
\hline \multicolumn{2}{|c|}{ Total bilirubin $(0.1-1.1 \mathrm{mg} / \mathrm{dL})$} \\
\hline Median (IQR) & $0.7(0.1-1.1)$ \\
\hline$<1.7$ & $39(88)$ \\
\hline$\geq 1.7$ & $5(11)$ \\
\hline No checked & 6 \\
\hline \multicolumn{2}{|l|}{ Direct bilirubin $(<0.4 \mathrm{mg} / \mathrm{dL})$} \\
\hline Median (IQR) & $0.3(0.2-0.4)$ \\
\hline$<0.5$ & $34(77)$ \\
\hline$\geq 0.5$ & $10(22)$ \\
\hline No checked & 6 \\
\hline \multicolumn{2}{|l|}{$\operatorname{ALT}(15-40$ IU/L) } \\
\hline Median (IQR) & $30.0(17.5-43.5)$ \\
\hline$<40$ & $30(66)$ \\
\hline$\geq 40$ & $15(33)$ \\
\hline No checked & 5 \\
\hline \multicolumn{2}{|l|}{ AST (15-40 IU/L) } \\
\hline Median (IQR) & $52.0(38.5-82.5)$ \\
\hline$<40$ & $12(26)$ \\
\hline$\geq 40$ & $33(73)$ \\
\hline No checked & 5 \\
\hline
\end{tabular}


Table 3. Continued

\begin{tabular}{|c|c|}
\hline Variables (Normal Range) & $\begin{array}{c}\text { Total }(n=50) \\
\text { No. }(\%)\end{array}$ \\
\hline \multicolumn{2}{|l|}{$\operatorname{ALP}(98-279$ U/L) } \\
\hline Median (IQR) & $204.0(153.0-296.5)$ \\
\hline$<280$ & $31(68)$ \\
\hline$\geq 280$ & $14(31)$ \\
\hline No checked & 5 \\
\hline \multicolumn{2}{|l|}{$\mathrm{CRP}(<20 \mathrm{mg} / \mathrm{L})$} \\
\hline Median (IQR) & $46.4(38.8-53.9)$ \\
\hline$<25$ & $1(2)$ \\
\hline$\geq 25$ & $47(97)$ \\
\hline No checked & 2 \\
\hline \multicolumn{2}{|l|}{ LAD (225-500 U/L) } \\
\hline Median (IQR) & $1063.0(622.0-1296.0)$ \\
\hline$<500$ & $5(12)$ \\
\hline$\geq 500$ & $34(87)$ \\
\hline No checked & 11 \\
\hline \multicolumn{2}{|l|}{ INR $(<1.3)$} \\
\hline Median (IQR) & $1.3(1.2-1.4)$ \\
\hline$<1.3$ & $26(55)$ \\
\hline$\geq 1.3$ & $24(48)$ \\
\hline No checked & 3 \\
\hline \multicolumn{2}{|l|}{$\operatorname{ESR}(<20 \mathrm{~mm} / \mathrm{h})$} \\
\hline Median (IQR) & $48.0(24.0-90.0)$ \\
\hline$<20$ & $7(18)$ \\
\hline$\geq 20$ & $31(81)$ \\
\hline No checked & 12 \\
\hline \multicolumn{2}{|l|}{$\mathrm{SpO}_{2}(>93 \%)$} \\
\hline Median (IQR) & $82.5(70.0-90.0)$ \\
\hline$<90$ & $37(74)$ \\
\hline$\geq 90$ & $13(26)$ \\
\hline \multicolumn{2}{|l|}{$\mathrm{pH}(7.36-7.44)$} \\
\hline Median (IQR) & $7.4(7.3-7.4)$ \\
\hline$<7.4$ & $25(53)$ \\
\hline$\geq 7.4$ & $22(47)$ \\
\hline \multicolumn{2}{|l|}{$\mathrm{CO}_{2}(36-44 \mathrm{~mm} \mathrm{Hg})$} \\
\hline Mean \pm SD & $39.1 \pm 8.3$ \\
\hline$<40$ & $24(51)$ \\
\hline$\geq 40$ & $23(49)$ \\
\hline \multicolumn{2}{|l|}{$\mathrm{HCO}_{3}(21-27 \mathrm{meq} / \mathrm{L})$} \\
\hline Mean \pm SD & $22.9 \pm 5.1$ \\
\hline$<24$ & $25(53)$ \\
\hline$\geq 24$ & $22(47)$ \\
\hline \multicolumn{2}{|l|}{ Chest CT scan } \\
\hline Consolidation & $23(46)$ \\
\hline Ground Glass & $50(100)$ \\
\hline Patchy Infiltration & $37(74)$ \\
\hline
\end{tabular}

WBC, white blood cel; INR, international normalized ratio; BUN, blood urea nitrogen; ALT, alanine aminotransferase; AST, aspartate aminotransferase; CRP, C-reactive protein; ALP, alkaline phosphataselactate; LDH, lactate dehydrogenase; ESR, erythrocyte sedimentation rate.

city is known as the first site of COVID-19 detection in the Middle East. In this study, we observed that older age, male gender, and preexisting co-morbidities (particularly cardiovascular disease) are the most common risk factors. Almost all patient probably died secondary to respiratory failure and ARDS.

Generally, COVID-19 has characteristics similar to SARS-CoV-2. ${ }^{13}$ In the present study, the main
Table 4. Complication Among Studied Patients

\begin{tabular}{|c|c|}
\hline Variables & $\begin{array}{c}\text { Total }(n=50) \\
\text { No. }(\%)\end{array}$ \\
\hline Sepsis & $18(36)$ \\
\hline Respiratory failure & $50(100)$ \\
\hline ARDS & $49(98)$ \\
\hline Septic shock & $7(14)$ \\
\hline Coagulopathy based on INR $>1.3$ & $24(48)$ \\
\hline Acute kidney injury & $31(62)$ \\
\hline Acidosis & $24(48)$ \\
\hline
\end{tabular}

ARDS, acute respiratory distress syndrome;

complications were respiratory failure and ARDS followed by the kidney injuries. In fact, COVID-19 can cause multi-organ damage. ${ }^{14-16}$ In previous reports, cardiovascular damage was considered at the top of the list of organ damage among COVID-19 patients. ${ }^{6,7,17}$ In the present study, the patients had not been evaluated regularly for cardiac events. Therefore, we cannot propose similar results in our patients. In fact, considering the common pre-existing cardiovascular problems as well as hypertension and diabetes among the patients, we suggest that cardiovascular events may be common factors that worsen the clinical situation of patients. A previous study indicated the association between cardiac events during pulmonary infection and following it. ${ }^{18,19}$ This mostly occurs in viral infections such as influenza. ${ }^{20,21}$ Notably, new cardiac events resulting from aggravation of preexisting cardiac problems were reported among patients with SARS. ${ }^{22}$ The mechanism of organ injuries in COVID-19 is not elucidated yet. It is proposed that the virus can directly attack organs or it can accelerate the inflammatory mechanisms. Furthermore, cytokine storm remains as the main hypothesis in this regard. ${ }^{22,6}$ Moreover, in older age, the defense mechanism is not intact. There is also cytokine dysregulation causing defects in viral protection. ${ }^{23}$ Also, it has been observed that older age increases the odds of mortality. The reports from China and the United States suggest that age above 65 years significantly increases the risk of mortality. Explanations for this result may include the points that were mentioned above. ${ }^{24,25}$

Recent studies have indicated associations with $\mathrm{CBC}$ differential including lymphocyte and neutrophil levels as well as hemoglobin value. ${ }^{26-28}$ In fact, many studies show an association of lymphopenia with poor outcomes. Indeed, neutrophilia may be associated with acute cardiac events and sepsis development that can increase the odd of mortality. Also, studies regarding $\mathrm{Hb}$ value are more interesting because a decline in $\mathrm{Hb}$ level has been shown to be associated with poor outcome and mortality in previous reports. ${ }^{29}$ However, in the present study, our patients did not have low $\mathrm{Hb}$ values, which may be related to rapid progression of the disease and also the fact that we considered the $\mathrm{Hb}$ concentration on admission. Altogether, we suggest the assessment of CBC with 
differential on admission and during the follow-up period of patients. This simple test can help the physicians to predict the patients' prognosis. Besides these findings, we must mention the elevated levels of CRP and LDH that are indicators of organ injuries and worsen the situation. Mardani et al indicated that values of LDH and CRP along with neutrophilia are associated with the presence of COVID-19. ${ }^{30} \mathrm{Li}$ et al also emphasized the important role of $\mathrm{LDH}$ in prognosis of patients. ${ }^{31}$ Along with these laboratory data, we also need to rely on the results of CT scans as well the quick SOFA score. The presence of consolidation in CT assessment and qSOFA score more than 2 were also associated with increased odds of mortality in previous reports. ${ }^{25}$

In conclusion, the presence of underlying diseases along with older age by themselves may worsen the outcome of patients. COVID-19 is a complex disease that cause multiorgan injuries. Therefore, simple alteration in laboratory value including $\mathrm{Hb}$ level, neutrophilia, and lymphopenia at the onset and during surveillance may provide a clue for poor prognosis.

\section{Authors' Contribution}

$\mathrm{MS}, \mathrm{AH}$ and SFG conceived and designed the analysis. SA, SJ, AJ, RA, MA, and ER collected the data. SJ and SA performed the analysis. MS wrote the paper.

\section{Conflict of Interest Disclosures}

There is no conflict of Interest.

\section{Ethical Statement}

The study protocol was approved by the ethics committee of Qom University of Medical Sciences (ID: IR.QUMS.rec.1398.154). This work was supported by Shahid Beheshti hospital, Qom University of Medical Sciences and Firoozgar hospital, Iran University of Medical Sciences. This research did not receive any specific grant from funding agencies in the public, commercial, or not-for-profit sectors.

\section{Acknowledgements}

We acknowledge all health-care workers involved in the diagnosis and treatment of patients at Shahid Beheshti hospital. We appreciate the time and efforts provided by Professor Farhad Zamani, Professor Hossein Ajdarkosh and MohamadHadi Karbalainia (Iran University of Medical Sciences) for their guidance in reviewing the manuscript. Also, thanks to Marzieh Hajbaba and Fatemeh Nikbakht (Iran University of Medical Sciences) for their help with data correction and software expertise. Also, we need to remember and pay our respects to our colleagues who became infected and died during their work.

\section{References}

1. Adhikari SP, Meng S, Wu YJ, Mao YP, Ye RX, Wang QZ, et al. Epidemiology, causes, clinical manifestation and diagnosis, prevention and control of coronavirus disease (COVID-19) during the early outbreak period: a scoping review. Allergy. 2020;9(1):29. doi: 10.1186/s40249-020-00646-x.

2. Chan JF, Yuan S, Kok KH, To KK, Chu H, Yang J, et al. A familial cluster of pneumonia associated with the 2019 novel coronavirus indicating person-to-person transmission: a study of a family cluster. Lancet. 2020;395(10223):514-23. doi: 10.1016/S0140-6736(20)30154-9.

3. Guo Y-R, Cao Q-D, Hong Z-S, Tan Y-Y, Chen S-D, Jin H-J, et al.
The origin, transmission and clinical therapies on coronavirus disease 2019 (COVID-19) outbreak-an update on the status. Mil Med Res. 2020;7(1):1-10. doi: 10.1186/s40779-02000240-0.

4. Hu Z, Song $C, X u$ C, Jin $G$, Chen $Y, X u$ X, et al. Clinical characteristics of 24 asymptomatic infections with COVID-19 screened among close contacts in Nanjing, China. Sci China Life Sci. 2020;63:706-711. doi: 10.1007/s11427-020-1661-4.

5. Chen H, Guo J, Wang C, Luo F, Yu X, Zhang W, et al. Clinical characteristics and intrauterine vertical transmission potential of COVID-19 infection in nine pregnant women: a retrospective review of medical records. Lancet. 2020;395(10226):809-15. doi: 10.1016/S0140-6736(20)30360-3.

6. Chen L, Li X, Chen M, Feng Y, Xiong C. The ACE2 expression in human heart indicates new potential mechanism of heart injury among patients infected with SARS-CoV-2. Cardiovasc Res. 2020;116(6):1097-100. doi: 10.1093/cvr/cvaa078.

7. Guan WJ, Ni ZY, HuY, Liang WH, Ou CQ, He JX, et al. Clinical Characteristics of Coronavirus Disease 2019 in China. N Engl J Med. 2020;382:1708-1720. doi: 10.1056/NEJMoa2002032.

8. Jiang F, Deng L, Zhang L, Cai Y, Cheung CW, Xia Z. Review of the Clinical Characteristics of Coronavirus Disease 2019 (COVID-19). J Gen Intern Med. 2020;35:1545-1549. doi: 10.1007/s11606-020-05762-w.

9. Pericàs J, Hernandez-Meneses M, Sheahan T, Quintana E, Ambrosioni J, Sandoval E, et al. COVID-19: from epidemiology to treatment. Eur Heart J. 2020;41(22):2092-112. doi: 10.1093/ eurheartj/ehaa462.

10. Shi S, Qin M, Shen B, Cai Y, Liu T, Yang F, et al. Association of cardiac injury with mortality in hospitalized patients with COVID-19 in Wuhan, China. JAMA cardiology. 2020;5(7):80210. doi:10.1001/jamacardio.2020.0950.

11. Chen J, Qi T, Liu L, Ling Y, Qian Z, Li T, et al. Clinical progression of patients with COVID-19 in Shanghai, China. J Infect. 2020. doi: 10.1016/j.jinf.2020.03.004.

12. Li B, Yang J, Zhao F, Zhi L, Wang X, Liu L, et al. Prevalence and impact of cardiovascular metabolic diseases on COVID-19 in China. Clin Res Cardiol. 2020;109(5):531-8. doi: 10.1007/ s00392-020-01626-9.

13. Yuen KS, Ye ZW, Fung SY, Chan CP, Jin DY. SARS-CoV-2 and COVID-19: The most important research questions. Cell Biosci. 2020;10:40. doi: 10.1186/s13578-020-00404-4.

14. Musa S. Hepatic and gastrointestinal involvement in coronavirus disease 2019 (COVID-19): What do we know till now?. Arab J Gastroenterol. 2020;21(1):3-8. doi: 10.1016/j. ajg.2020.03.002.

15. Perico L, Benigni A, Remuzzi G. Should COVID-19 Concern Nephrologists? Why and to What Extent? The Emerging Impasse of Angiotensin Blockade. Nephron. 2020;144:21321. doi: 10.1159/000507305.

16. Tan W, Aboulhosn J. The cardiovascular burden of coronavirus disease 2019 (COVID-19) with a focus on congenital heart disease. Int J Cardiol. 2020;309:70-7. doi: 10.1016/j. ijcard.2020.03.063.

17. Zhu H, Rhee JW, Cheng P, Waliany S, Chang A, Witteles RM, et al. Cardiovascular Complications in Patients with COVID-19: Consequences of Viral Toxicities and Host Immune Response. Curr Cardiol Rep. 2020;22(5):32. doi: 10.1007/s11886-02001292-3.

18. Kochi AN, Tagliari AP, Forleo GB, Fassini GM, Tondo C. Cardiac and arrhythmic complications in patients with COVID-19. J Cardiovasc Electrophysiol. 2020;31(5):1003-8. doi: 10.1111/ jce.14479.

19. Long B, Brady WJ, Koyfman A, Gottlieb M. Cardiovascular complications in COVID-19. Am J Emerg Med. 2020;38:15047. doi: 10.1016/j.ajem.2020.04.048.

20. Blackburn R, Zhao H, Pebody R, Hayward A, Warren-Gash C. Laboratory-confirmed respiratory infections as predictors of 
hospital admission for myocardial infarction and stroke: timeseries analysis of English data for 2004-2015. Clin Infect Dis. 2018;67(1):8-17. doi: 10.1093/cid/cix1144.

21. Brack MC, Lienau J, Kuebler WM, Witzenrath M. Cardiovascular sequelae of pneumonia. Curr Opin Pulm Med. 2019;25(3):257-62. doi: 10.1097/MCP.0000000000000584.

22. Oudit GY, Kassiri Z, Jiang C, Liu PP, Poutanen SM, Penninger $J M$, et al. SARS-coronavirus modulation of myocardial ACE2 expression and inflammation in patients with SARS. Eur J Clin Invest. 2009;39(7):618-25. doi: 10.1111/j.13652362.2009.02153.x.

23. Rea IM, Gibson DS, McGilligan V, McNerlan SE, Alexander HD, Ross OA. Age and Age-Related Diseases: Role of Inflammation Triggers and Cytokines. Front Immunol. 2018;9:586. doi: 10.3389/fimmu.2018.00586.

24. CDC COVID-19 Response Team. Severe Outcomes Among Patients with Coronavirus Disease 2019 (COVID-19) United States, February 12-March 16, 2020. MMWR Morb Mortal Wkly Rep. 2020;69(12):343-6. doi: 10.15585/mmwr. $\mathrm{mm} 6914 \mathrm{e} 4$.

25. Zhou F, Yu T, Du R, Fan G, Liu Y, Liu Z, et al. Clinical course and risk factors for mortality of adult inpatients with COVID-19 in Wuhan, China: a retrospective cohort study. Lancet. 2020;395(10229):1054-62. doi: 10.1016/S01406736(20)30566-3.
26. Li H, Chen K, Liu M, Xu H, Xu Q. The profile of peripheral blood lymphocyte subsets and serum cytokines in children with 2019 novel coronavirus pneumonia. J Infect. 2020;81(1):11520. doi: 10.1016/j.jinf.2020.04.001.

27. Yun H, Sun Z, Wu J, Tang A, Hu M, Xiang Z. Laboratory data analysis of novel coronavirus (COVID-19) screening in 2510 patients. Clin Chim Acta. 2020;507:94-7. doi: 10.1016/j. cca.2020.04.018.

28. Zuo Y, Yalavarthi S, Shi H, Gockman K, Zuo M, Madison JA, et al. Neutrophil extracellular traps in COVID-19. JCI Insight. 2020;5(11):e138999. doi: 10.1172/jci.insight.138999.

29. Terpos E, Ntanasis-Stathopoulos I, Elalamy I, Kastritis E, Sergentanis TN, Politou M, et al. Hematological findings and complications of COVID-19. Am J Hematol. 2020;95(7):834847. doi: 10.1002/ajh.25829.

30. Mardani R, Ahmadi Vasmehjani A, Zali F, Gholami A, Mousavi Nasab SD, Kaghazian H, et al. Laboratory Parameters in Detection of COVID-19 Patients with Positive RT-PCR; a Diagnostic Accuracy Study. Arch Acad Emerg Med. 2020;8(1):e43

31. Li X, Xu S, Yu M, Wang K, Tao Y, Zhou Y, et al. Risk factors for severity and mortality in adult COVID-19 inpatients in Wuhan. J Allergy Clin Immunol. 2020;146(1):110-8. doi: 10.1016/j.jaci.2020.04.006. 